\title{
Blood Product Pathogen Reduction
}

National Cancer Institute

\section{Source}

National Cancer Institute. Blood Product Pathogen Reduction. NCI Thesaurus. Code C133282.

Exposure to a chemical and/or radiation based processing system intended to reduce the risk of transfusion-transmitted infections in blood and blood components. 